\section{SOME NEW HYBRIDS}

The recent purchase by the Indian government of two zebra-horse hybrids from Prof. J. Cossar Ewart, of Edinburgh University, Scotland, has called attention to the work of this gentleman, and, incidentally, to the experiments in cross-breeding of $\mathrm{Mr}$. Carl Hagenbeck, the animal dealer at Hamburg, who has for some seven years past given serious consideration to this subject. During this comparatively short period $\mathrm{Mr}$. Hagenbeck has produced an entirely new variety of sheep, deer, and pheasant by crossing the stronger, wilder species with tame, domestic specimens.

It should be stated at once, perhaps, that the one aim in conducting these experiments has been to obtain a stronger and better animal-that is to say, better blood. That this has been accomplished in the case of the zebra-horse cross there is not the slightest doubt. The new animal, which has been named the zebrule, has been produce been produced with the object of taking up the work of the ordinary military mule. It is a little larger than the average mule, and when once broken to harness is much more tractable and far more intelligent. Furthermore, $t \mathrm{~h}$ e new animal does not possess that stubborn will and dangerous $\mathrm{tricks}$ often

found in the common mule. It is also hardy, a good trotter, very sure of its footing, and capable of adapting itself to great changes of climate and temperature.

Prof. Ewart seriously commenced his experiments nine years ago. He obtained a fine, healthy zebra stallion, "Matopo," now the sire of many zebrules. The first hybrid was born in August, 1896, at Penicuik, in Midlothian, Scotland, the dam being a pony, selected from a first-class breed, the sire, of course, be ing "Matopo," The foal proved strong and hardy, very easily broken to saddle and harness, while its intelligence surprised those in charge of it. The animal was produced merely for scientific purposes, but it was such a success that Prof. Ewart came to the conclusion that the new hybrid would be an ideal animal for ordnance and commissariat work. several in his park at Stellingen, near Hamburg, and when in that city recently the writer went for a drive behind two of these interesting creatures.

Full-grown they stand about 14 hands high, and have a girth measurement of about 63 inches. They are therefore somewhat larger than a mule. At first sight they strike one as strange, the zebra striping in some instances being very distinct, though, of course, by no means so conspicuous as in the wild zebra. The answer to the reins instantly, are not at all nervous of electric cars or traffic, and fast trotters. gists is the lion and tiger cross, a number of which may now be seen at the Hagenbeck establishment in Hamburg. The oldest is four years of age, and is a fine animal, called "Prince." $\mathrm{He}$ was recently seen performing with several other animals in one of the Hagenbeck trained groups in New York When only three years of age he weighed five hundredweight and measured 10 feet from the tip of his tail to the tip of his nose, and stood four feet high to the top of the shoulder. The peculiarity of this beast is that he has a tiger's body and a lion's head, the stripes, of course not being so distinct as in the common tiger. Prince's father was a Senegal lion and his mother a Bengal tiger. This one animal is valued by its owner at $\$ 10,000$.

"The first successful experiment I made in the crossing of animals," said Mr. Hagenbeck, in speaking of this side of his interesting work, "was about seven years ago, when I crossed a leopard and a puma. The only living animal of the litter, which, fortunately, was a very healthy one, I sold some time ago to the Berlin Zoological Garden, where it is still in the collection. I am now busy endeavoring to obtain a new variety of sheep by crossing the giant sheep of Central Asia with our common domestic animal."

Sportsmen will be par-

r. Lawrence Hagenbeck and a Team of Zebra-Horse Hybrids.

Prof. Ewart in speaking of the hybrid in his book, "A Guide to Zebra Hybrids," says: "Zebrules are usually better able to take care of themselves than pure-bred animals, are more alert, more active, and altogether more vigorous and intelligent. From the first, zebra hybrids are more friendly, more curious and confiding than ordinary foals. With time and care most of them can be trained to any kind of work. It is almost impossible and far from safe to break in a young mule by itself, but quite possible to break in by itself a zebra hybrid."

It was hoped that the British War Office would take the new animal, but it stolidly refused to touch them. It is as well, perhaps, that the animals are to be tried first in India, where it is well known the natives manage their mules with more tact and patience than the British soldier. The animals have already arrived at ticularly interested in the new pheasant which the Hamburg establishment has produced. It has been obtained by crossing pheasants from Central Asia with the European variety. The result is a larger bird, much stronger on the wing, and more prettily marked. The new pheasant very much resembles the English or common American pheasant in appearance. It is somecovered that it is very quick on the wing and not so easy to bring to the ground. Mr. Hagenbeck has succeeded in securing several broods of these pheasants. The first of these were obtained in April of last year. They were quickly snapped up by the Duke of Bedford and Lord Rothschild, who own extensive shooting arger portion of them. Several broods were obtained again at the beginning of this year, and the birds are

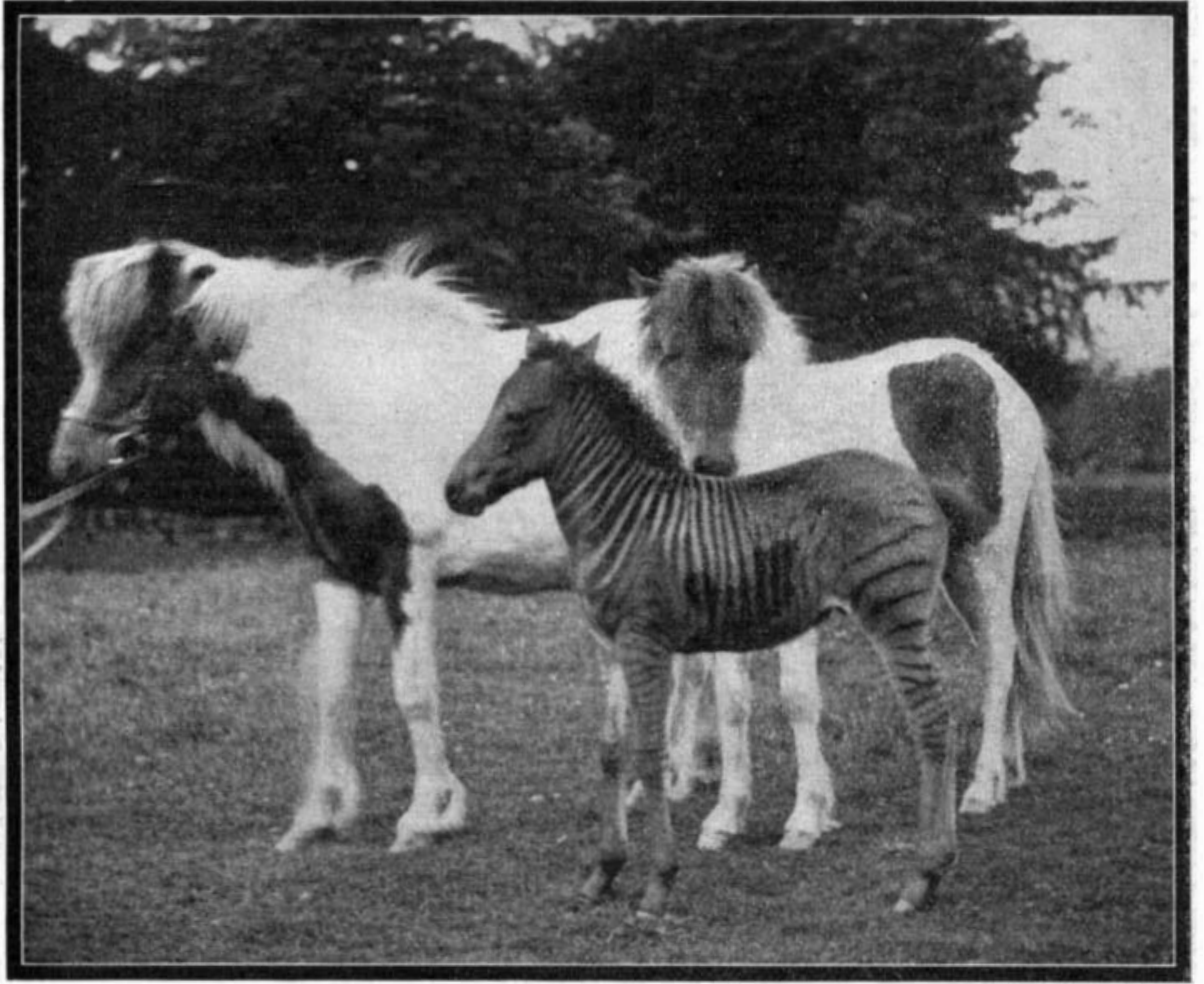

Iceland Pony and Her Two Foals. the Smaller of Which is a Zebra Cross.

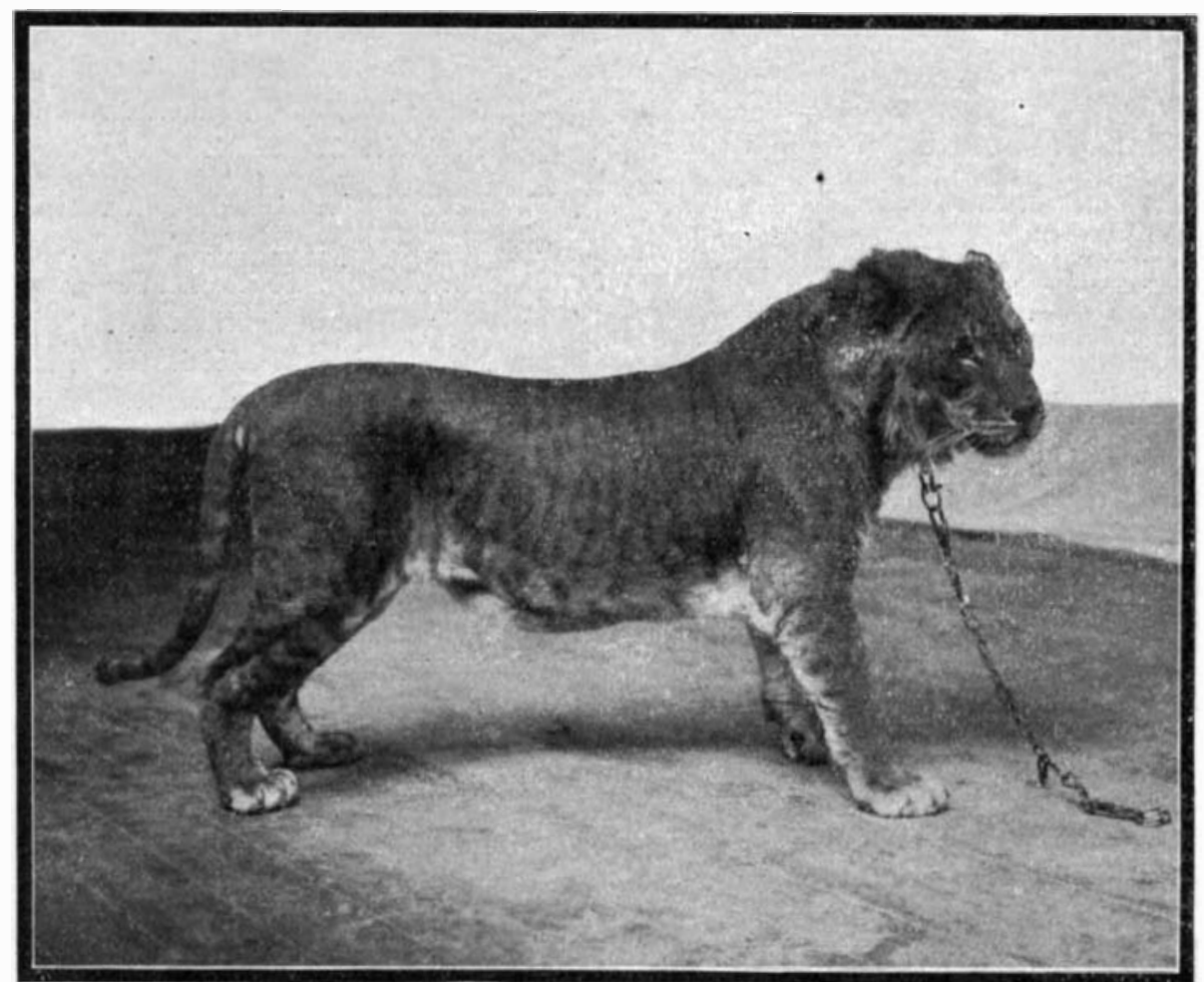

The Nine Months Old Progeny of a Lion and a Tiger.

SOME NEW HYBRIDS.

The experiments were therefore continued, and a number of zebrules bred from thoroughbreds, halfArabs and Clydesdales. Several $c i$ these were purchased by Carl Hagenbe $i-$ of Famburg Indeed, he had already bought the two which have been dispatched to India, but willingly gave them up to the Indian government when they decided to take them, as he is convinced from his experience and handling of the zebrule that it will be the mule of the twentieth century. He is endeavoring to get the German government to take some of these animals for use in their army. He has their destination, Quetta, and are now undergong a series of tests as to their suitability for mountain battery work. Although no official report has been received, it has been stated that the animals fulfill all the requirements set down by the Indian government. Indeed, so well have they behaved that a number of drives have been organized in the East Africa Protectorate for the capture of young zebra stallions for exportation to India, Jamaica, and elsewhere for breeding purposes.

A hybrid that has attracted the attention of zoolo- all doing well. For years the European pheasant has been gradually declining, but with the introduction o the Asiatic variety it' has received a new lease of life. In the same way several new varieties of deer have been secured by crossing Persian fallow deer with ordinary European deer.

Sleeping car service has been inaugurated on the electric lines ptween Columbus, Ohio, and Indian apolis, Ind. The ars are complete sleepers, and are equipped with 600-ıorsepower motors. 


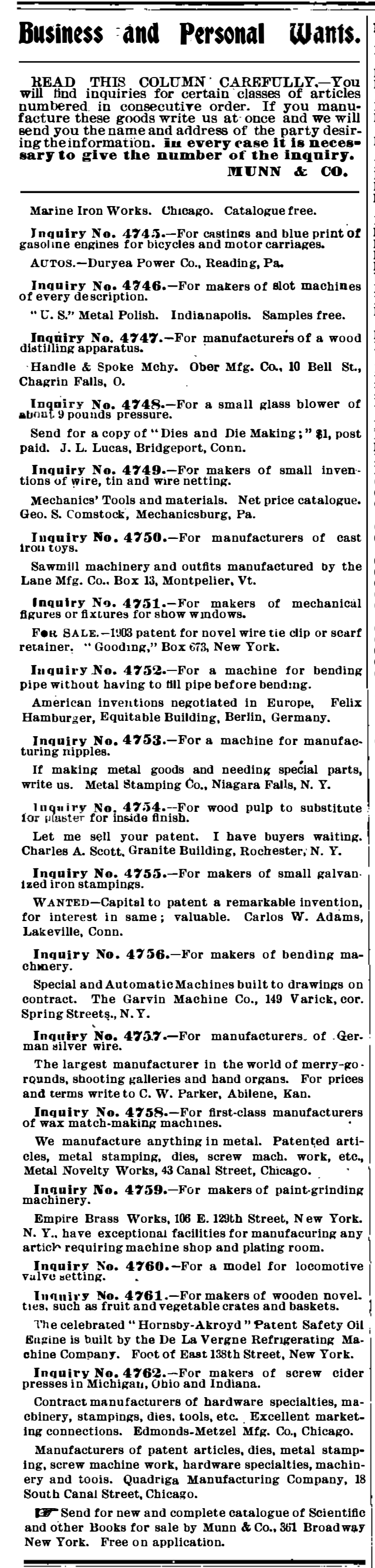

INDEX OF INVENTIONS

For which Letters Patent of the United States were Issued for the Week Ending October 27, 1903 ,

AND EACH BEARING THAT DATE

S See note at end of list about copies of these patents.

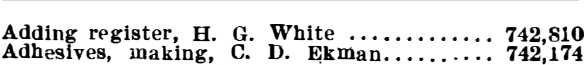

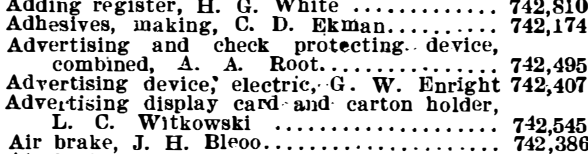

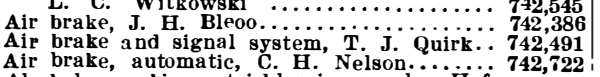

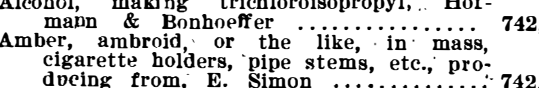
docing from, E. Simon
Angle finder, J., A. Traut...
Animal shears, H. v. Dunn
Animal trap, C. W. Gillis Anima trap, C. W. Gillis $\ldots \ldots$
Annunciator, line, H. P. Clausen
Autocar dust guard, W. H. Brow
Automatic coupling, F. M. \& Automatic indicator, W. E. Laird

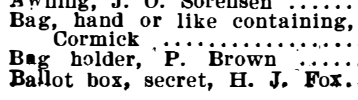
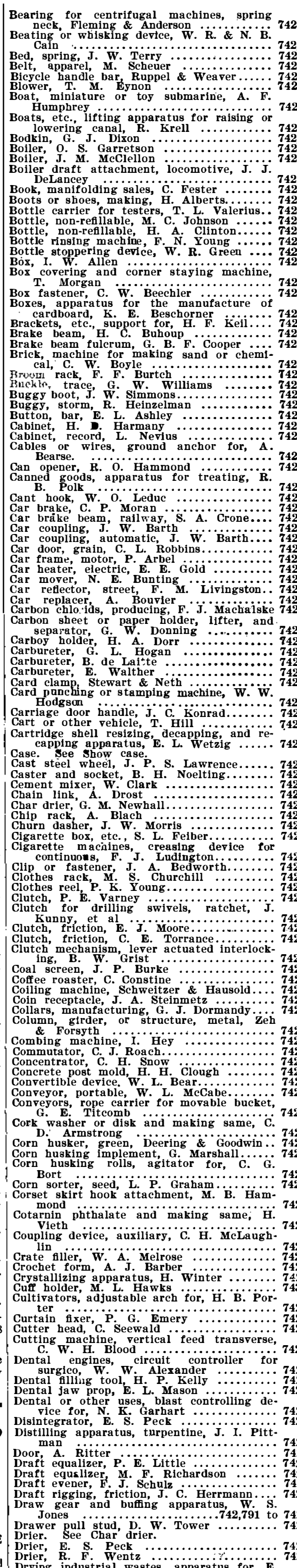

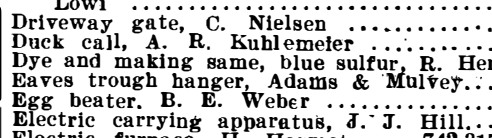

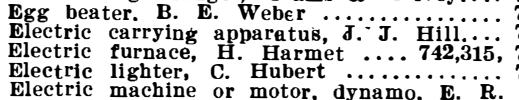

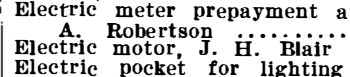

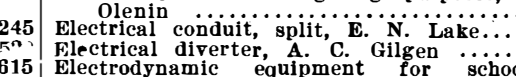

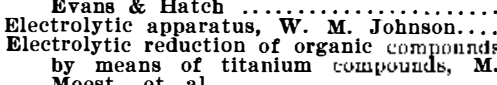

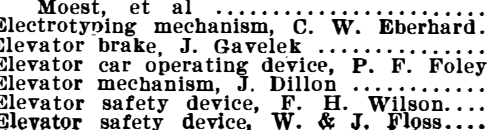

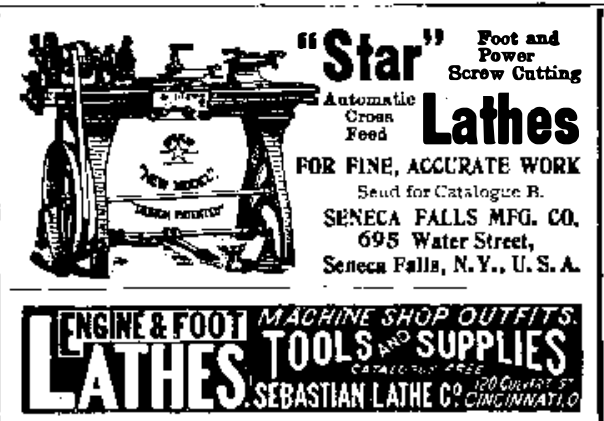

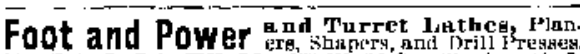

SCHIEREN'S WEEKLY ADVICE:

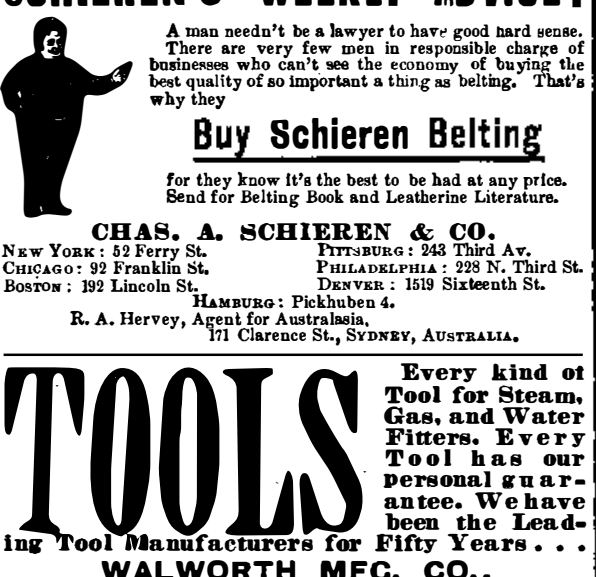
128 TO 136 FEDERAL ST." Boston', MASS. Veeder Ratchet and Rotary Counters
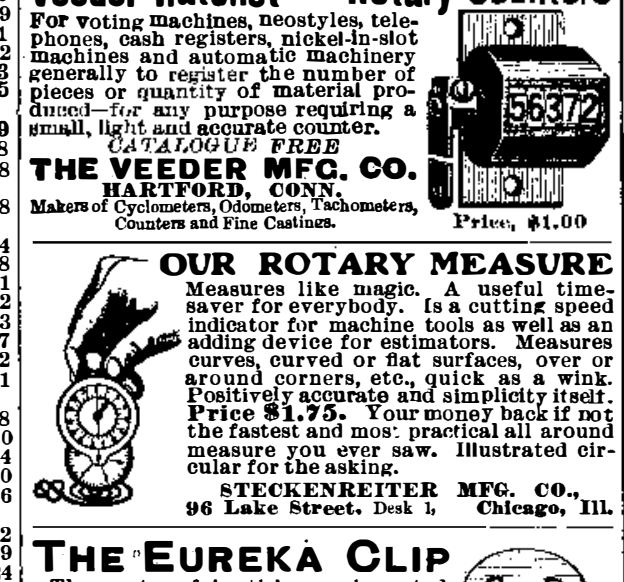

The"Eureka Clip

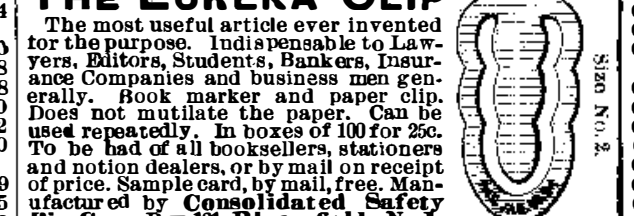

and
and

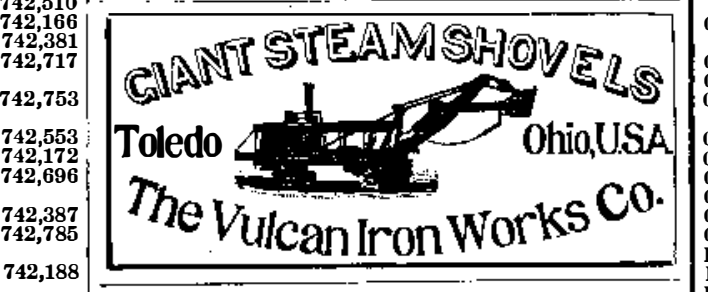

\section{YOU ARE EASY}

742,5,4,
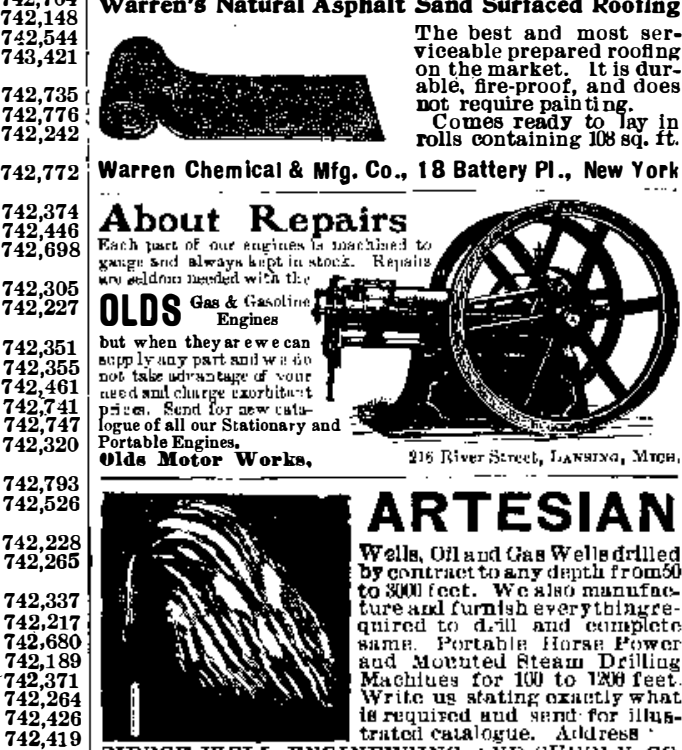

ARTESIAN
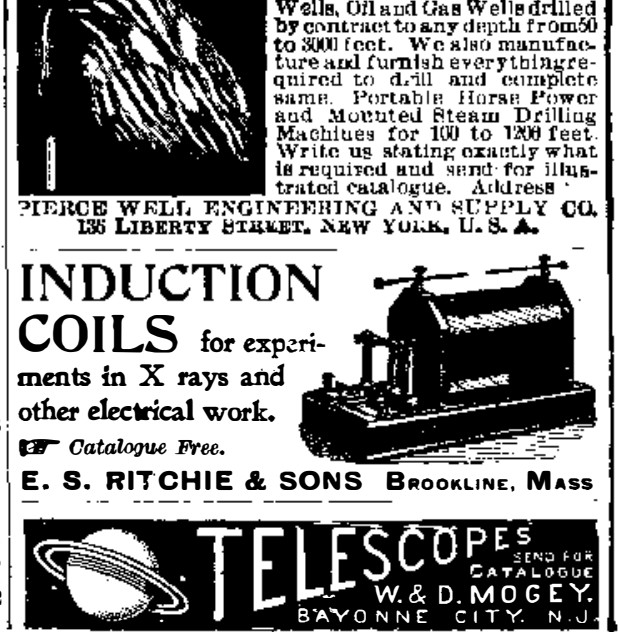

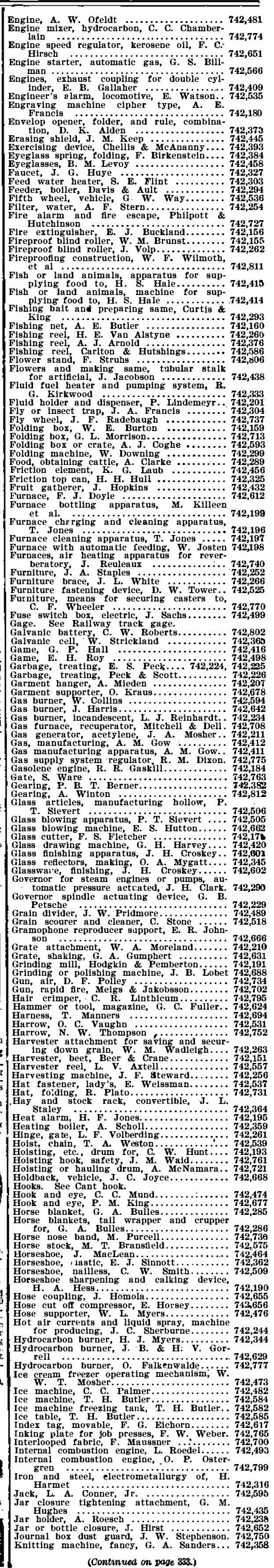

